\title{
Amelogenesis Imperfecta - Literature Review
}

\author{
GemimaaHemagaran ${ }^{1}$,Arvind. $\mathrm{M}^{2}$ \\ ${ }^{I}$ B.D.S.,Saveetha Dental College, Chennai, India \\ ${ }^{2}$ B.D.S., M.D.S., Dip Oral medicine, Prof. of Oral Medicine, Saveetha Dental College, Chennai, India.
}

\begin{abstract}
Amelogenesis Imperfecta (AI) is a group of inherited disorder of dental enamel formation in the absence of systemic manifestations. AI is also known as Hereditary enamel dysplasia, Hereditary brown enamel, Hereditary brown opalescent teeth. Since the mesodermal components of the teeth is normal, this defect is entirely ectodermal in origin. Variants of AI generally are classified as hypoplastic, hypocalcified, or hypomineralised types based on the primary enamel defect. The affected teeth may be discoloured, sensitive or prone to disintegration, leading to loss of occlusal vertical dimensions and very poor aesthetics. They exists in isolation or associated with other abnormalities in syndromes. It may show autosomal dominant, autosomal recessive, sex-linked and sporadic inheritance patterns. Mutations in the amelogenin, enamelin, and kallikrein-4 genes have been demonstrated to different types of AI.
\end{abstract}

Keywords: AmelogenesisImperfecta, Hypoplastic, Hypocalcific, Hypomineralised.

\section{Introduction:}

Amelogenesis imperfecta (AI) is a term for a clinically and genetically heterogeneous group of conditions that affect the dental enamel, occasionally in conjunction with other dental, oral and extraoral tissues.[1]

Dental enamel formation is divided into secretory, transition, and maturation stages. During the secretory stage, enamel crystals grow primarily in length. During the maturation stage, mineral is deposited exclusively on the sides of the crystallites, which grow in width and thickness to coalesce with adjacent crystals.[2]The main structural proteins in forming enamel are amelogenin, ameloblastin, and enamelin.

During the secretory stage, enamel proteins are being secreted along with proteases. This is a major factor in determining the composition of the enamel matrix. Changes in this mechanism by genetic defects of proteins or proteinases can result in the pathological changes during the enamel formation. [3]

\section{Definition:}

AI represents a group of conditions, genomic in origin, which affect the structure and clinical appearance of the enamel of all or nearly all the teeth in a more or less equal manner, and which may be associated with morphologic or biochemical changes elsewhere in the body. [1]

\section{Etiology:}

Amelogenesis imperfecta is a group of inherited defects of dental enamel formation that show both clinical and genetic heterogeneity. Dental enamel is a highly mineralised tissue with over $95 \%$ of its volume occupied by unusually large, highly organised, hydroxyapatite crystals. This formation is highly controlled through interactions of a number of organic matrix molecules that include enamelin, (ENAM; 4q21) amelogenin (AMELX; Xp22.3-p22.1), ameloblastin (AMBN; 4q21), tuftelin (TUFT1; 1q21), amelotin (AMELOTIN; 4q13), dentine sialophosphoprotein (DSPP; 4q21.3) and a variety of enzymes such as kallikrein 4 (KLK4; 19q13.3q13.4) and matrix metalloproteinase 20 (MMP20; 11q22.3-q23) [4,5]

\section{Classification:}

Many classification have been evolved since the original division into hypoplastic and hypocalcified types in 1945. Some are exclusively based on phenotypes i.e, their appearance but others have used the phenotype as the primary discriminate and the mode of inheritance as a secondary factor in diagnosis. [6]

Witkop(1989) classified AI into four major categories based primarily on phenotype (hypoplastic, hypomaturation, hypocalcified, hypomaturation-hypoplastic with taurodontism) subdivided into 15 subtypes by phenotype and secondarily by mode of inheritance. [7]

\begin{tabular}{|l|l|}
\hline YPE 1. & HYPOPLASTIC \\
\hline TYPE $1 A$ & Hypoplastic, pitted autosomal dominant \\
\hline TYPE $1 B$ & Hypoplastic, local autosomal dominant \\
\hline TYPE $1 C$ & Hypoplastic, local autosomal recessive \\
\hline TYPE $1 D$ & Hypoplastic, smooth autosomal dominant \\
\hline TYPE $1 E$ & Hypoplastic, smooth X-linked dominant \\
\hline
\end{tabular}


AmelogenesisImperfecta- Literature Review

\begin{tabular}{|c|c|}
\hline TYPE $1 F$ & Hypoplastic, rough autosomal dominant \\
\hline TYPE $1 G$ & Enamel agenesis, autosomal recessive \\
\hline TYPE 11. & HYPOMATURATION \\
\hline TYPE 11A & Hypomaturation, pigmented autosomal recessive \\
\hline TYPE $11 B$ & Hypomaturation, $X$-linked recessive \\
\hline TYPE 11C & Hypomaturation, snow-capped teeth, $\mathrm{X}$-linked \\
\hline TYPE 11D & $\begin{array}{llll}\begin{array}{l}\text { Hypomaturation, snow-capped teeth, autosomal } \\
\text { dominant }\end{array} & & \\
\end{array}$ \\
\hline TYPE 111A & AUTOSOMAL DOMINANT \\
\hline TYPE 111B & AUTOSOMAL RECESSIVE \\
\hline TYPE $1 \mathrm{~V}$. & $\begin{array}{l}\text { HYPOMATURATION-HYPOPLASTIC WITH } \\
\text { TAURODONTISM }\end{array}$ \\
\hline TYPE 1VA & $\begin{array}{l}\text { Hypomaturation-hypoplastic } \\
\text { autosomal dominant }\end{array}$ with $\quad$ taurodontism, \\
\hline TYPE 1VB & $\begin{array}{l}\text { Hypoplastic-hypomaturation } \\
\text { autosomal dominant }\end{array}$ with $\quad$ taurodontism, \\
\hline
\end{tabular}

\section{Hypoplastic Ai:}

All of the hypoplastic AI subtypes are characterized by the primary feature of deficient amount of enamel formed. The decreased amount of enamel varies in the different subtypes and can be characterized by enamel that is pitted, has grooves or furrows, has large areas of missing or very thin enamel surrounded by normal enamel, or enamel that is very thin over the entire tooth crown. Witkop's clinical classification of hypoplastic AI recognizes seven subtypes. [6]

Quantitative defect occurs when the enamel does not reach normal thickness either due to local or general factors. Clinically, the crown size varies from small to normal, small teeth may lack proximal contacts, colour varies from normal to opaque white - yellow brown.[7] (Fig 1a) Enamel may be rough, smooth, pitted, grooved, locally hypoplastic or the complete tooth crown may appear with thin enamel.(Fig 1b) Eruption disturbances may occur. Anterior open bite of skeletal origin may occur.[8] Radiographically, the enamel has normal to slightly reduced contrast, thickness of enamel is reduced and density of enamel is reduced.[9]

It is inherited by Autosomal dominant, recessive, or X-linked. In families with X-linked inheritance, females may show normal and hypoplastic enamel alternating in a vertical pattern due to lyonisation. [10]

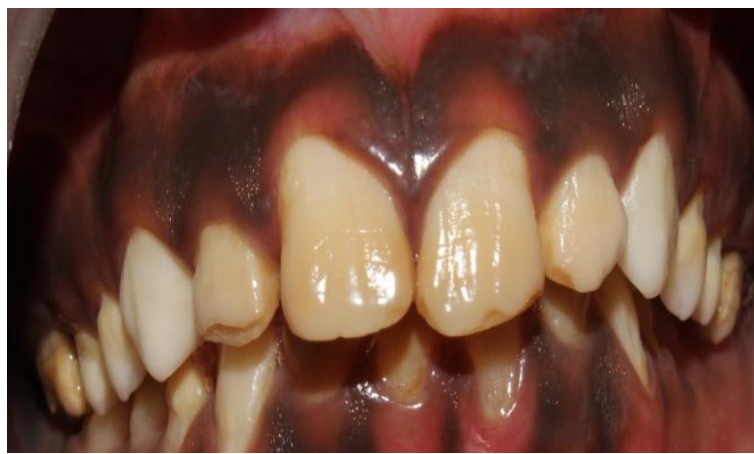

Fig 1a: Hypoplastic enamel labial view

Fig 1b:Hypoplastic enamel occlusal view

IV. Hypomaturation Ai:

Qualitative defect of the enamel is seen when the enamel is insufficiently mineralized. The teeth are morphologically normal at the time of eruption, but may chip away posteruptively, especially in the occlusal areas.

Clinically, the colour of teeth here varies from creamy opaque to marked yellow/brown, surface of teeth soft and rough, sensitivity due to dentinal exposure.Open bite malocclusion is a common feature. [11,12] (Fig 2a)The enamel thickness is normal but often chips off and abrades away easily. (Fig 2b, 2c) Radiographically, there is reduced differentiation between enamel and dentin which may be difficult to verify. Enamel has contrast similar to or greater than dentin, unerupted crowns have normal morphology radiographically.[7,8,9,10] (Fig 2d)

It is inherited by autosomal dominant, recessive, or X-linked. In families with X-linked inheritance, females may have vertical stripes of opaque enamel altering with bands of normal enamel due to lyonisation.[13] 


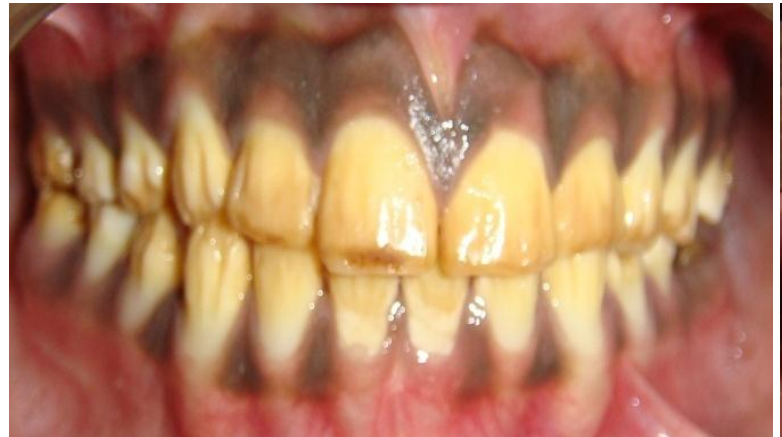

Fig 2a: Creamy opaque, yellow/ brown hypomaturation of enamel

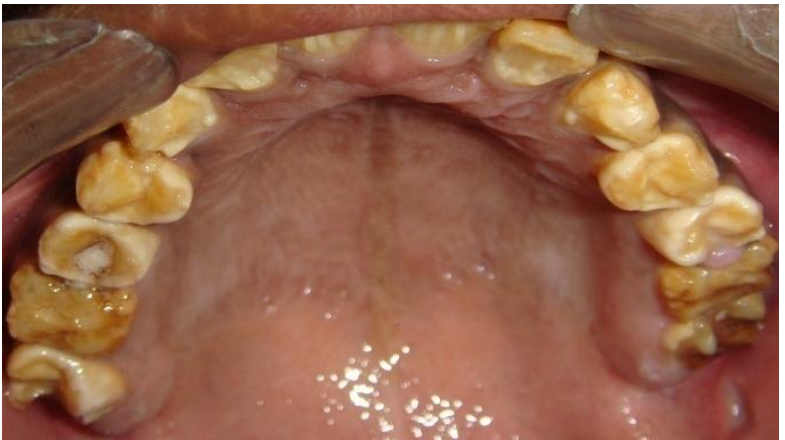

Fig 2b: Occlusal view of hypomaturation enamel
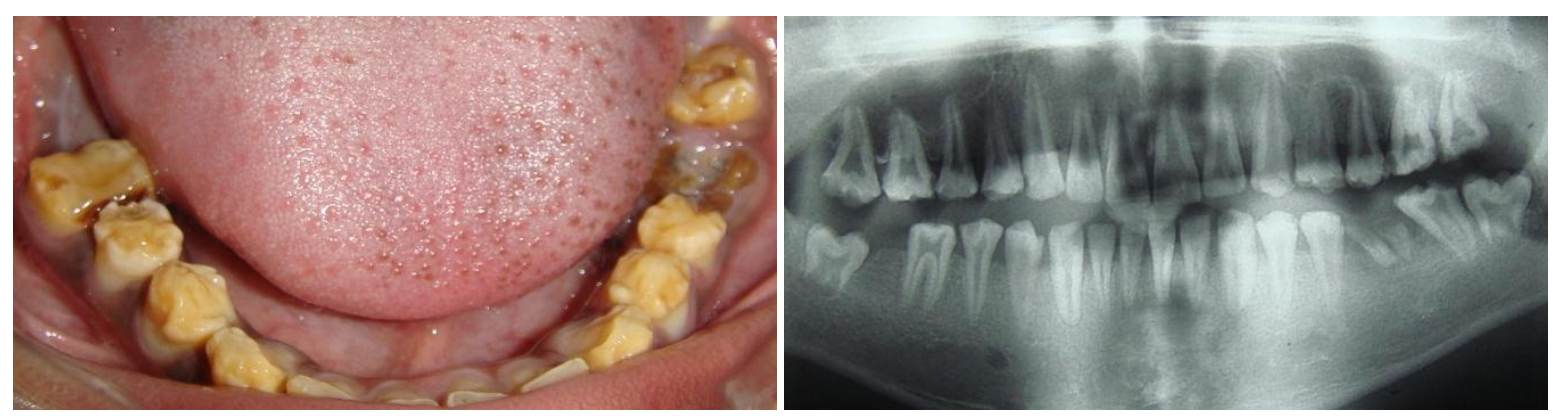

Fig 2c: Pitted enamel surface occlusal view

Fig 2d: Orthopantomogram

\section{HYPOCALCIFIED AI:}

Qualitative defect occurs when the enamel is insufficiently mineralised and soft. on comparison with hypo maturation variety, the degree of mineralization is markedly reduced.

Clinically, the crown appears opaque white to yellow-brown, soft rough enamel surface, dental sensitivity and very poor aesthetics.(Fig 3a) There is early loss of enamel due to severe hypomineralization. Normal thickness of enamel at eruption that often chips and abrades easily posteruptively. (Fig 3b) There may be delayed eruption of teeth. An anterior open bite of skeletal origin may be seen. Accumulation of a large amount of supragingival calculus is evident. Radiographically, there is reduced contrast between enamel and dentin. $[7,8,9,10]$

It is inherited by Autosomal dominant, recessive genes [11]

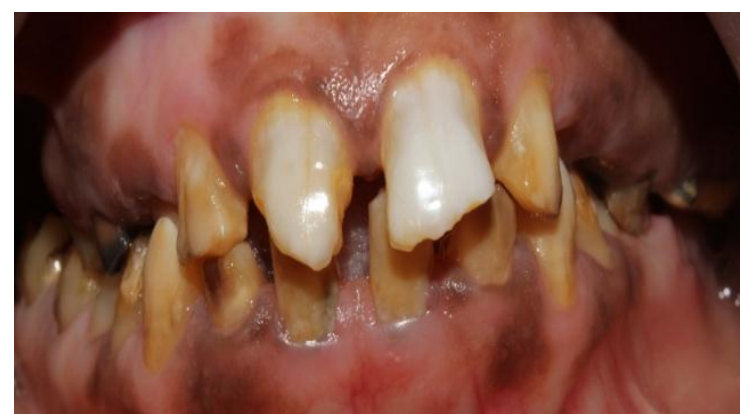

Fig 3a:Unaesthetic labial view of hypomineralised enamel

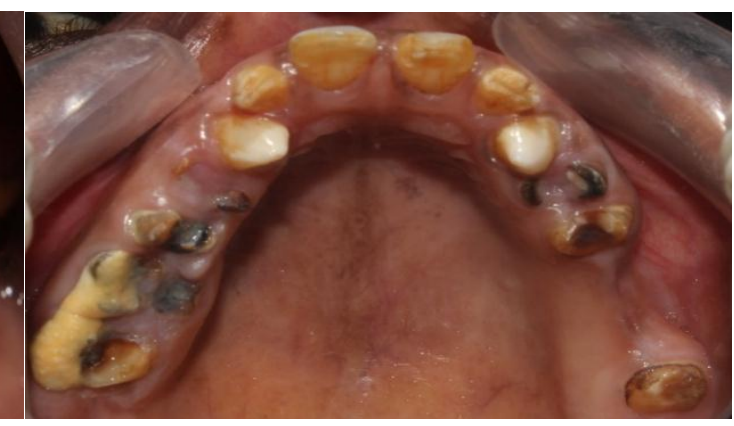

Fig 3b: Occlusal view

\section{Hypomaturation-HypoplasticTaurodontism:}

Clinically, crown appears white/yellow- brown mottled. Teeth can appear smaller than normal and they lack proximal contacts. The enamel thickness is reduced much. The crowns appears to havehypo mineralisedareas and pits. Radiographically, enamel contrast is normal to slightly > dentin, and shows large pulp chambers. Inherited by Autosomal dominant. [10,11]

\section{Management of AI:}

Treatment is based on the principles of prevention before intervention. However, in these patient's cases, intervention will likely to be earlier in life and more radical than for others.[10] The supportive clinical care 
needed by these individuals is substantial both in terms of clinical and emotional demands. It's been reported that patients suffering from AI have their teeth covered with pieces of paper, chewing gum or other materials in order to mimic an ordinary appearance. [14,15]

For primary dentition, the progression of treatment is describes as a temporary phase followed by a transitory phase. Preformed metal crowns are restored for the posterior teeth and either polycarbonate crowns or composite restorations are used for anterior tooth. Children with AI are not without a malocclusion, so it's important that a restorative dentist and an orthodontist are involved with the paediatric dentist in the care plan from the child's early age. [16]

Full-mouth rehabilitation of an adult with AI can be demanding. Different occlusal schemes have been advocated. Canine-guided occlusion was chosen to protect the posterior teeth because it is technically easier to achieve than group function. All ceramic restorations were used for the premolars and anterior teeth because of their aesthetics, biocompatibility, and improved physical properties. [17]

Prior to restorative treatment it is important to have optimal gingival health. Gingivitis and bleeding gums makes placement of bonded and esthetic restorations extremely difficult. Preventive interventions, such as professional cleaning, the use of antimicrobial oral rinses (e.g. chlorhexidine), and excellent oral hygiene, help to achieve healthy soft tissue prior to and after restorative care.[18,19]

\section{Conclusion:}

The psychosocial effects of amelogenesis imperfecta on affected individuals, even in children are significant. Dental practitioners should consider the social implications for these patients and intervene to relieve their suffering. Full-mouth rehabilitation of AI patients entails good understanding of the disease, management tactics for severely damaged dentition, knowledge of maxillo-mandibular physiology and dental materials science.

\section{References:}

[1]. Aldred MJ, Crawford PJM, Savarirayan R: Amelogensisimperfecta - a classification and catalogue for the 21st century. Oral Dis, 2003 9:19-23

[2]. Simmer JP, Hu JC. Expression, structure and function of enamel proteinases. Connect tissue Res.2002: 43;(2-3);441-9 review

[3]. Li W, Gao C, Yan Y, Denbesten P. X-linked amelogenesisimperfecta may result from decreased formation of tryosine rich amelogenin peptide (TRAP). Arch Oral Biol.2003; 48:177-83; 2003

[4]. Iwasaki K, Bajenova E, Somogyi-Ganss E, Miller M, Nguyen V, Nourkeyhani H, Gao Y, Wendel M, Ganss B: Amelotin-a Novel Secreted, Ameloblast-specific Protein. J Dent Res 2005, 84:1127-1132.

[5]. Peter JM Crawford, Michael Aldred, Agnes Bloch-Zupan: Amelogenesisimperfecta. Orphanet Journal of Rare Diseases 2007, 2:17 doi:10.1186/1750-1172-2-17

[6]. Witkop CJ, Sauk JJ: Heritable defects of enamel. In oral facial genetics edited by : Stewart R, Prescott G, St.Louis: CV Mosby company; 1976:151-226

[7]. Witkop CJ Jr. Amelogenesisimperfecta, dentinogenesisimperfecta and dentin dysplasia revisited: problems in classification. Oral Pathol 1998, 17:547-553

[8]. Aldred MJ, Crawford PJM: Amelogenesisimperfecta-towards a new classification. Oral diseases 1995, 1:2-5

[9]. Hart PS, Hart TC, Simmer JP, Wright JT: A nomenclature for X-linked amelogenesisimperfecta. Arch Oral Bio 2002, 47:255-260

[10]. Iwaski K, Bajenova E, Somogyi-Ganss E, Miller M, Nguyen V, et al Amelotin-a Novel Secreted, Ameloblast-specific Protein. J Dent Res 2005,84:1127-1132.

[11]. Wright J. The diagnosis and treatment of dentinogenesisimperfecta and amelogenesisimperfecta. Hellenic Dent J 1993;2:17-24.

[12]. Guru, Sunil, Raghav Kumar, Hemant, Siddharth, Neera Sharma, AmelogenesisImperfecta- A literature Review. Dept of Oral medicine and Radiology, D.J,College of Dental Sciences and Research, Modinagar 2011. doi 10.5602/2229-3624.50.

[13]. Millet C, Duprez JP,Multidisciplinary management of a child with severe open bite and amelogenesisimperfecta..J Contemp Dent Pract. 2013 Mar 1;14(2):320-6.

[14]. W.KimSeow, Clinical diagnosis and management strategies of amelogenesisimperfecta variants, Pediatric Dentistry Nov/Dec 1993vol:15 number 6

[15]. Aldred MJ, Crawford PJM, Savariryan R, Savulescu J: It's only teeth-is there a limit to genetic testing? Clinical Genet 2003, 63:333-339

[16]. Bouvier D, Duprez JP, Bois D: Rehabilitation of young patients with amelogenesisimperfeta: a report of two cases. ASDC J Dent Child 1996, 63:443-447

[17]. Christensen GJ, Procelain-fused-to-metal vs non-metals crown. J Am Dent Assoc 1999;130:409-411

[18]. Ergun G, Kaya BM, Egilmez F, Cekic-Nagas I. Functional and esthetic rehabilitation of a patient with amelogenesisimperfecta.J Can Dent Assoc. 2013;79:d38

[19]. Wright JT, Waite P, Mueninghoff L, Sarver DM. The multidisciplinary approach managing enamel defects. JADA 1991;122:62-65. 